\title{
Dotuan \\ Patricia Anne Brennan AM, MB Bs, phD, FACLM, MForensmed
}

PATRICIA BRENNAN was born in Hurstville, Sydney, on 15 April 1944. She attended St George Girls High School and graduated in medicine from the University of Sydney in 1968.

After residency at Sydney Hospital, she worked at the Sudan Interior Mission hospitals in Jos, Nigeria, and Galmi, Niger. Patricia became aware of the poverty and powerlessness of many African women and the vulnerability of the powerless to hidden sexual and domestic abuse.

Patricia returned to Australia in 1973 to become Haematology Registrar at Prince of Wales Hospital, Randwick, while also holding the position of general practice consultant for the Sudan Interior Mission. In 1977, she established a solo general practice at Summer Hill, which she maintained until 1986. During this time, Patricia also became Assistant Medical Director of the Sydney Square Breast Clinic.

Throughout her life, Patricia accepted and sought opportunities to work against oppression and injustice. Each phase of her life was characterised by questioning, passion and intellectual rigour.

In the 1980s and early 1990s, her defining work was a voluntary commitment outside of medicine to reform the position of women in the church, especially in her own Anglican church. As founding President of the Movement for the Ordination of Women from 1985 to 1989, she was a charismatic and inspirational leader with a ready wit and great presence, who galvanised support and sometimes opposition to the cause. She believed ordination would achieve a transformational change in the role of all women in the church and have a symbolic power in the wider fight against abuse and coercion.

In 1995, she worked with World Vision, assessing funded health programs, including programs to combat sexual assault and to manage post-traumatic stress in children in refugee camps in Gaza and the West Bank, Israel.

In 1996, while undertaking her doctorate in medical anthropology, Patricia commenced as a medical officer with the Liverpool/Fairfield Sexual Assault Service and, in 2001, she became its Medical Director. This resulted in the next stage of her vocation: calling on the medical and wider community to recognise the widespread and longlasting trauma caused by sexual assault and family violence. She completed a Masters in Forensic Medicine from Monash University, developed specialist pathways for training and, at the Royal Prince Alfred Hospital, became the first Staff Specialist in Clinical Forensic Medicine specialising in sexual assault appointed to an emergency department in New South Wales. She was a Fellow of the Australasian College of Legal Medicine, a member of the Forensic and Medical Sexual Assault Clinicians Australia, and a founding committee member of the Australasian Association of Forensic Physicians.

In 2009, she became acting Medical Director of the Clinical Forensic Medical Unit of the NSW Police Force, and was appointed a Visiting Fellow in Law at the University of NSW in 2010.

She pushed for medical rigour in a field of medicine where there was a history of ill founded medical opinion contributing to grave injustices: the return of children to situations of abuse, failed prosecutions due to inadequate medical evidence and, occasionally, false convictions.

Patricia's achievements were recognised with a Bicentennial Woman of Achievement Award in 1988 and, in 1993, she was made a Member of the Order of Australia for services to the community, particularly as founding President of the Movement for the Ordination of Women.

Patricia was a doctor of ready wit and apt speech who exercised leadership on big picture issues with passionate intelligence. She could be discouraged by frustration at the slowness of change, but she always returned with energy and creativity to the cause. All her struggles were motivated by a bold vision and a sense of calling. She died on 6 March 2011, 4 months after being diagnosed with pancreatic cancer. She is survived by her husband Robert, children Kate, Peter and James, and grandson Gabriel.

Rosemary A Isaacs doi: 10.5694/mjall.11000 